\title{
Efficient recovery of superhydrophobic wax surfaces on solid wood
}

\author{
Benjamin Arminger ${ }^{1,2}$ [D $\cdot$ Wolfgang Gindl-Altmutter $^{1} \cdot$ Christian Hansmann $^{2}$
}

Received: 11 June 2021 / Accepted: 25 January 2022 / Published online: 6 February 2022

(c) The Author(s) 2022

\begin{abstract}
Superhydrophobic surface coatings have enormous potential to protect wood from excessive water uptake. Unfortunately, such coatings often require toxic chemicals or complex fabrication methods, and their mechanical stability is very limited. As an alternative, highly water-repellent wood surfaces with mean water contact angles (WCAs) of $160^{\circ}$ were prepared by straightforward spray-deposition of alkyl ketene dimer (AKD) wax microparticles. While water repellency was unaffected by static loading with a cast iron weight, prolonged rubbing resulted in a strong reduction in WCA to $125^{\circ}$ since the spherical wax microstructure was largely destroyed by the acting shear forces. Thermal treatment of such a degraded surface at $80^{\circ} \mathrm{C}$ led to an almost full recovery (WCA $155^{\circ}$ ) of water repellency. Microscopy and thermal analysis revealed that exposure to temperatures above the melting range and subsequent slow cooling enable self-assembly of AKD into leaf-shaped microstructures, which are responsible for the high WCA observed. It is proposed that the thermally induced self-recovery ability will greatly enhance the utility and service life of AKD-based superhydrophobic wood surfaces and make them suitable for multiple practical applications.
\end{abstract}

\section{Introduction}

Research on highly water-repellent surfaces, commonly defined by static water contact angles (WCAs) of $150^{\circ}$ or higher (Feng et al. 2002; Yan et al. 2011), is motivated by early publications on artificial superhydrophobic surfaces (Onda et al. 1996; Shibuichi et al. 1996) as well as an increasing understanding of fundamental biological hydrophobisation strategies. Besides the famous example of the self-cleaning properties of lotus (Nelumbo nucifera) leaves, a high number of superhydrophobic natural surfaces has been investigated (Barthlott and Neinhuis 1997; Barthlott et al. 2010; Bhushan and Jung 2011; Carré and Mittal 2009; Koch

Benjamin Arminger

benjamin.arminger@boku.ac.at

Wolfgang Gindl-Altmutter

wolfgang.gindl@boku.ac.at

Christian Hansmann

c.hansmann@wood-kplus.at

1 Department of Material Science and Process Engineering, University of Natural Resources and Life Sciences Vienna, Konrad Lorenz Straße 24, 3430 Tulln, Austria

2 Wood K plus, Competence Centre for Wood Composites and Wood Chemistry, Konrad Lorenz Straße 24, 3430 Tulln, Austria and Ensikat 2008). All revealed similarities that are now commonly understood as the crucial requirements for the preparation of superhydrophobic surfaces, i.e. the use of low surface free energy materials in combination with a distinctive micro- or nanostructured surface provided by tubules, platelets, rodlets or hairs, grooves, fissures, and many more (Darmanin and Guittard 2015; Zhang et al. 2008). It is well known that surface roughness enhances the wetting properties of a given surface, as proposed by Wenzel (1936), who added a roughness factor $r$ to Young's principles on contact angles on ideal surfaces (Bormashenko 2009; Young 1805).

Moreover, wood protection by means of superhydrophobic surface coatings has attracted increasing attention for several years (Liu et al. 2011; Wang et al. 2011a, c). Thin layers with sophisticated chemistry and architecture that hinder liquid water uptake by wood have many potential advantages compared to bulk wood modification, for example rapid application, reduced consumption of chemicals, negligibly small weight gain, and the preservation of mechanical and optical wood properties to a large extent. Wood as a renewable, load bearing material faces increasing demand. In many use cases it requires protection against excessive water uptake to prevent damage from dimensional instabilities or biological decay. Superhydrophobic surfaces dramatically reduce the wetting of hygroscopic wood substrates and hence have the ability to minimize the adsorption of liquid 
water. Since the first superhydrophobic wood surfaces have been reported (Liu et al. 2011; Wang et al. 2011a), a variety of interesting fabrication strategies were proposed, but the well-known issues for technological application-elaborate multi-step processes (Bai et al. 2019; Xia et al. 2020) or the use of harmful chemicals (Bao et al. 2019; Pandit et al. 2020) - mostly remained. To maintain the sustainable character of wood products, particular consideration should be given to the use of environmentally-friendly materials also in coatings. In this regard, waxes seem to be a good solution, as they are successfully applied by numerous plants and already find broad application in the hydrophobisation of many different substrates (Saji 2020). Similarly, natural oils may provide environmentally friendly superhydrophobic wood surface coatings (Janesch et al. 2020).

Recently, a water-based spraying process for the straightforward and economic deposition of particles produced from alkyl ketene dimer (AKD), a widely used paper sizing agent, onto wood surfaces was presented (Arminger et al. 2019). This method provides WCAs of $160^{\circ}$ and higher and is fast-paced, economic, and environmentally-friendly. On the downside, surfaces produced using this approach suffer from very limited durability since the fine nano-platelet structures responsible for the required level of hydrophobicity are typically very fragile (Dalawai et al. 2020; Verho et al. 2011; Zhu et al. 2011). Even approaches involving more durable, robust superhydrophobic surfaces on wood substrates showed significant contact angle reductions after exposure to mechanical stresses (Jia et al. 2018; Shah et al. 2017). Since lack of mechanical strength is inherent to many nanostructured superhydrophobic surfaces, approaches to recovery and self-healing are of high interest. As with the concept of superhydrophobicity itself, self-healing of such surfaces is a biomimetic approach. For example, the observation of regenerating epicuticular wax crystals on damaged (superhydrophobic) leaf surfaces has inspired technological solutions (Huth et al. 2018; Koch et al. 2009; Neinhuis et al. 2001). Two main techniques to achieve self-healing are distinguished. One is to store hydrophobic components inside rough materials, which are released upon mechanical deterioration, thus restoring surface properties (Chen et al. 2015, 2016; Li et al. 2010; Sam et al. 2019; Wang et al. 2011b; Xue et al. 2014). The second approach is based on the regeneration of topographic structures themselves (Chen et al. 2016; Manna and Lynn 2013; Sam et al. 2019). Since even the most resilient superhydrophobic surfaces will wear over time, self-healing ability is greatly desired to fulfill the requirements of practical applications (Sam et al. 2019).

In the present study, AKD wax-based superhydrophobic wood surfaces were prepared as recently reported by Arminger et al. (2019). Their wetting behavior (WCAs and sliding angles) and surface structure (via scanning electron microscopy) were investigated before the surfaces were exposed to mechanical normal and shear stresses. Since it is known that AKD structures are capable of changing shape upon assuming thermodynamically stable or meta-stable conformations (Fang et al. 2008), different thermal treatments were applied to the surfaces to investigate whether the surface roughness and concomitant superhydrophobicity could be recovered. The resulting wetting behavior and topography are compared to the initial, intact surfaces and it is attempted to clarify the formation mechanism of the recovered structures by means of thermogravimetric investigations of the AKD wax.

\section{Materials and methods}

\subsection{Materials}

European beech (Fagus sylvatica) wood was sanded to grit size 320 . Specimens of $60 \times 60 \times 5 \mathrm{~mm}^{3}$ in longitudinal $\times$ radial $\times$ tangential direction, respectively, were cut from one lamella to ensure comparable chemical and topographic wood surface properties. AKD (CAS No. 144245-85-2) FennoWax C-18EX with predominant chain lengths of $\mathrm{C}_{16}-\mathrm{C}_{18}$ attached to the oxetane ring was provided by Kemira Chemie GesmbH (Krems, Austria).

\subsection{Methods}

Preparation of the aqueous wax dispersion and its application to wood Lentoid AKD wax flakes were melted in boiling deionized water at a concentration of $10 \mathrm{~g} \mathrm{~L}^{-1}$ and emulsified for 7 min using a KSB-200 (KeMar GmbH, Munich, Germany) blender at its maximum rotational speed. The liquid/liquid emulsion was subsequently cooled slowly to room temperature, causing particles to solidify. The resulting solid/liquid suspension was filtered through a nylon sieve with a retention threshold of $125 \mu \mathrm{m}$. The particle size distribution, the polydispersity index (PDI), and the $\zeta$-potential of the AKD wax particles within the dispersion were investigated by means of dynamic light scattering (DLS) using a Zetasizer Nano ZS (Malvern Panalytical GmbH, Kassel, Germany) instrument. On the same day of the preparation, three measurements on duplicate samples of the dispersion (each consisting of 13 runs) were taken for the calculation of the particle size, and two measurements on duplicate samples (12 runs) for determining the $\zeta$-potential.

For the preparation of superhydrophobic wood surfaces, the dispersion was sprayed on the substrates using an Evolution (Harder \& Steenbeck GmbH \& Co. KG, Norderstedt, Germany) airbrush tool equipped with a $0.15 \mathrm{~mm}$ nozzle and the corresponding needle. After spraying, the samples were oven-dried for $10 \mathrm{~min}$ at $45^{\circ} \mathrm{C}$. The spraying-drying cycle 
was repeated three more times and the samples were kept at $45^{\circ} \mathrm{C}$ for $15 \mathrm{~h}$ after the final spraying repetition.

Characterization of hydrophobic wood surfaces Static sessile drop water contact angles of $10 \mu \mathrm{l}$ drop volume were measured on the treated samples using a semiautomatic Drop Shape Analyzer-DSA 30S (Krüss GmbH, Hamburg, Germany). Measurement duration was $10 \mathrm{~s}$, four frames per second were used for the contact angle calculation of the builtin image analysis software according to the Young-Laplace model. A number of eight water droplets were placed on all intact and mechanically loaded samples, four droplets were measured on the cut specimens directly after the different recovery treatments. The same number and volume of drops were used for sliding angle measurements, which were performed on a custom-built measurement device. Both the camera angle of contact angle measurements and the water drop roll-off direction were set perpendicular to the wood grain direction to avoid overestimation of contact angles and underestimation of sliding angles. Scanning electron microscopy (SEM) was performed on a Quanta 250 FEG microscope (FEI, Hillsboro, Oregon, USA). Samples were sputter-coated with gold and scanned in high vacuum with an acceleration voltage of $10 \mathrm{kV}$.

Mechanical loading Two superhydrophobic samples of $60 \times 60 \mathrm{~mm}^{2}$ surface area were exposed to the compression stress of a $10 \mathrm{~kg}$ cast iron weight which was placed on a $50 \times 50 \mathrm{~mm}^{2}$ aluminum sheet of $1 \mathrm{~mm}$ thickness on the center of the samples. The total duration of exposure was 30 min which was interrupted for contact angle and sliding angle measurements after 10 and $20 \mathrm{~min}$, before the final wetting and SEM investigations were carried out. Shear stresses by means of thumb rubbing using disposable gloves were applied to six intact wood samples. Half of the samples were exposed for $30 \mathrm{~s}$, the other half was loaded for $60 \mathrm{~s}$ per sample. With each of the recurring finger rubbing movements, a normal pressure of $0.5-1.5 \mathrm{~kg}$ was applied, which was observed on a scale positioned below the wood samples.

Recovery of the surface structures After the loaded specimens were examined for wetting properties, they were cut into quarters of approximately $30 \times 30 \mathrm{~mm}^{2}$. One of these quarters of each specimen was exposed to recovery condition R-I, i.e. storage at room temperature. Another quarter of each specimen was exposed to R-II, i.e. heating to $80^{\circ} \mathrm{C}$ within $1 \mathrm{~h}$ in an oven and subsequent storage at room temperature. The remaining two quarters of each cut specimen were exposed to a temperature ramp referred to as R-III, which consisted of $1 \mathrm{~h}$ of heating to $80^{\circ} \mathrm{C}$ (together with the specimens of R-II). Afterwards, the oven was turned off and allowed to slowly cool to room temperature. All treatments were performed overnight for $16 \mathrm{~h}$ before the next wetting examinations were carried out. The climate within the oven was recorded and the temperature profiles of the recovery conditions are summarized in Fig. 1.

Thermoanalysis of AKD The thermal analysis of AKD was performed on a simultaneous thermal analysis device (STA 409PC/PG, Erich Netzsch GmbH \& Co. Holding KG, Selb, Germany). An exact amount of solid AKD (6 mg) was weighed in an aluminum crucible and sealed with a pierced lid. The analysis was conducted using a two-cycle heating and cooling ramp $\left(10-100{ }^{\circ} \mathrm{C}, 100-10{ }^{\circ} \mathrm{C}\right)$ at a heating rate of $10 \mathrm{~K} \mathrm{~min}^{-1}$ under nitrogen atmosphere to investigate phase transformations of the material. The heat flow was recorded and analyzed using the Netsch Proteus 3.8.2 software package.

\section{Results and discussion}

\subsection{Properties of dispersed AKD particles}

The size of wax particles considerably affects the wettability of treated wood surfaces (Arminger et al. 2019). Therefore, the aqueous AKD dispersion used for spraying was examined by means of dynamic light scattering. Particle size analysis revealed a bidisperse particle size distribution with a main peak at $845 \pm 32 \mathrm{~nm}$ and a second peak at $135 \pm 36 \mathrm{~nm}$, which were responsible for $92 \%$ and $8 \%$ of the intensity, respectively (Fig. 2). The resulting $\mathrm{Z}$-average mean particle size was $515 \pm 6 \mathrm{~nm}$ at a mean polydispersity index of $0.336 \pm 0.017$. The measured
Fig. 1 Ambient temperature of the three different recovery conditions

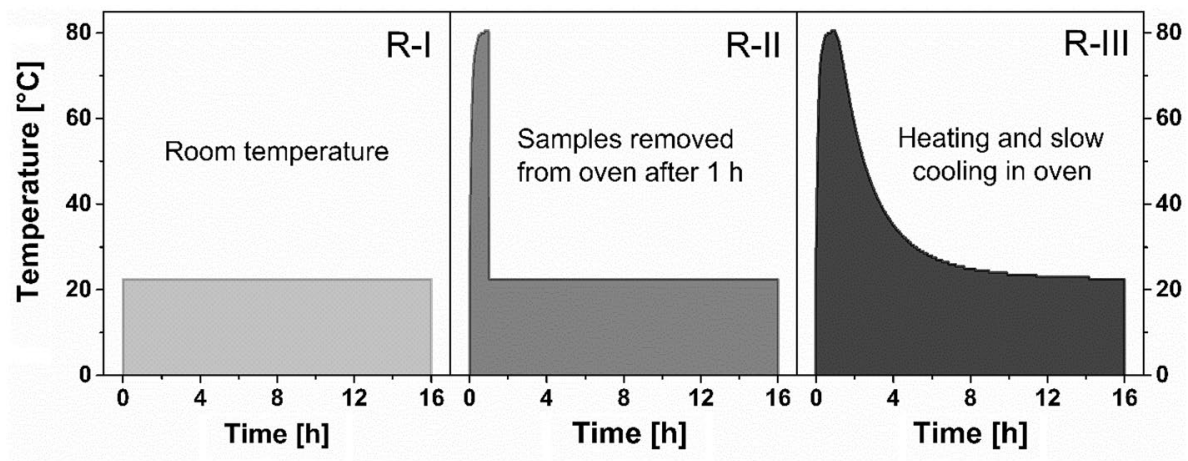




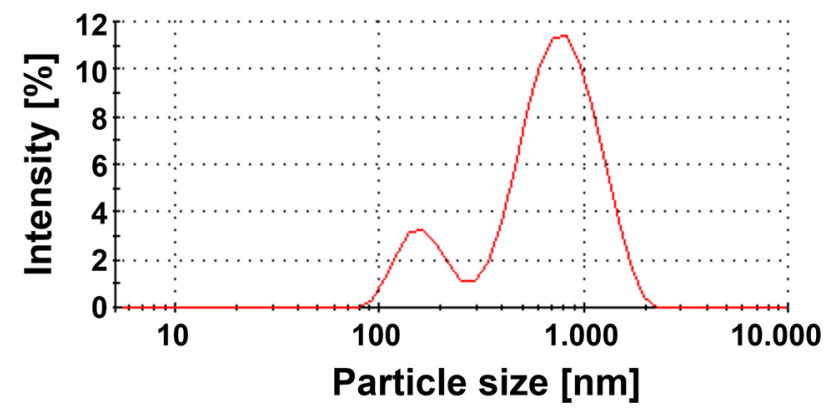

Fig. 2 Representative particle size distribution of the aqueous alkyl ketene dimer dispersion measured on the same day of its preparation

$\zeta$-potential of $-25.9 \pm 0.3 \mathrm{mV}$ indicated good dispersion stability, which was confirmed by the fact that no apparent change of the dispersions was observed within the first weeks after the preparation.

\subsection{Thermal analysis of AKD}

The group of Tsujii and co-workers, who were the first to prepare superhydrophobic surfaces from AKD (Onda et al. 1996; Shibuichi et al. 1996), investigated the formation mechanism of flake-like, fractal AKD wax structures. They clarified that the spontaneous formation of particular structures from AKD and other potentially superhydrophobic waxes originated from phase transformations from a meta-stable to a stable crystalline form. In their experiments, wax crystals had been quenched during solidification by rapid cooling from a melt and therefore solidified to a (partially) metastable state in a first step. Consequently, wax platelets spontaneously grew to a more stable form during the crystal transition, which was discovered by observing differences in thermogravimetric behavior between stored and freshly solidified samples (Fang et al. 2007, 2008; Minami et al. 2008; Shibuichi et al. 1997). Corresponding to these thermoanalytical investigations, two successive thermograms of the same AKD sample are depicted in Fig. 3. The endothermic band around $67^{\circ} \mathrm{C}$ in cycle 1 corresponds to the melting of the stable crystalline phase of AKD that was stored for approximately two years at room temperature. During a second heating cycle, which was started just after the sample was cooled down to $10{ }^{\circ} \mathrm{C}$, a new small exothermic peak appeared around $52{ }^{\circ} \mathrm{C}$ and indicated a partially metastable crystalline state. According to the literature (Fang et al. 2008; Minami et al. 2008; Shibuichi et al. 1997), the presence of this state enabled the formation of structure from a smooth AKD surface. The exo-peak was again followed by a clear endothermal peak indicating melting of AKD.

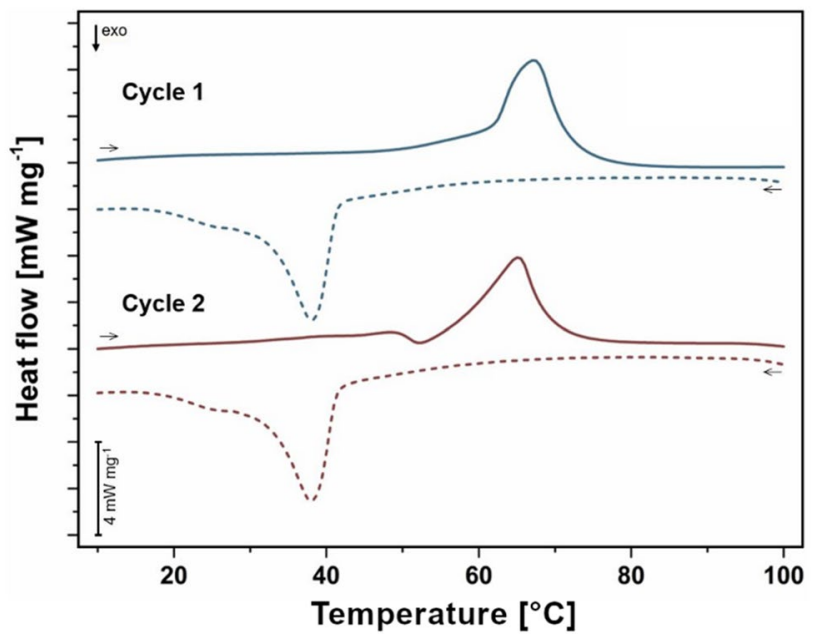

Fig. 3 STA thermograms of AKD after more than two years of storage at room temperature (Cycle 1) and reheating and cooling immediately after solidification (Cycle 2)

\subsection{Wetting behavior before and after mechanical loadings}

Wood coatings and surface treatments aim to protect the material from excessive water uptake, which makes water contact angle (WCA) measurements an indispensable tool for wetting characterization. After the AKD dispersion was applied onto wood surfaces, all samples were clearly classified as superhydrophobic with an overall WCA mean of $160.4 \pm 3.4^{\circ}$ (Fig. 4/A4). Wide ranges of single drop sliding angles from $6^{\circ}$ to $69^{\circ}$ were observed on all samples, resulting in an overall mean value of $22.4^{\circ}$ for drop volumes of $10 \mu \mathrm{l}$. Good protection against liquid water uptake can be expected from these surfaces, even though significantly lower sliding angles can be found in the literature (Jia et al. 2016; Wu et al. 2016). Sliding angles strongly depend on the drop volume (Pierce et al. 2008) and if, in the case of wetting, small drops did not roll off a slightly declined surface, they would agglomerate to form a larger drop to which a lower sliding angle would apply. Detailed results of all sliding angle measurements are provided in the Supplementary Information section. As shown in SEM images (Fig. 4/ A1-3), the treated wood surface was covered with AKD spheres with diameters ranging from below 1 to approximately $3 \mu \mathrm{m}$. It is proposed that the high specific surface area AKD coating observed with SEM is responsible for the high WCAs measured. The size of the spheres found on the surface is in good agreement with the particle size distribution found in the dispersion used for treatment (Fig. 2). In addition to the predominant spheres, a small number of flake-like platelet structures typical for AKD as reported by several authors before (Ejenstam et al. 2013; Onda et al. 1996; Quan et al. 2009) was also observed. 


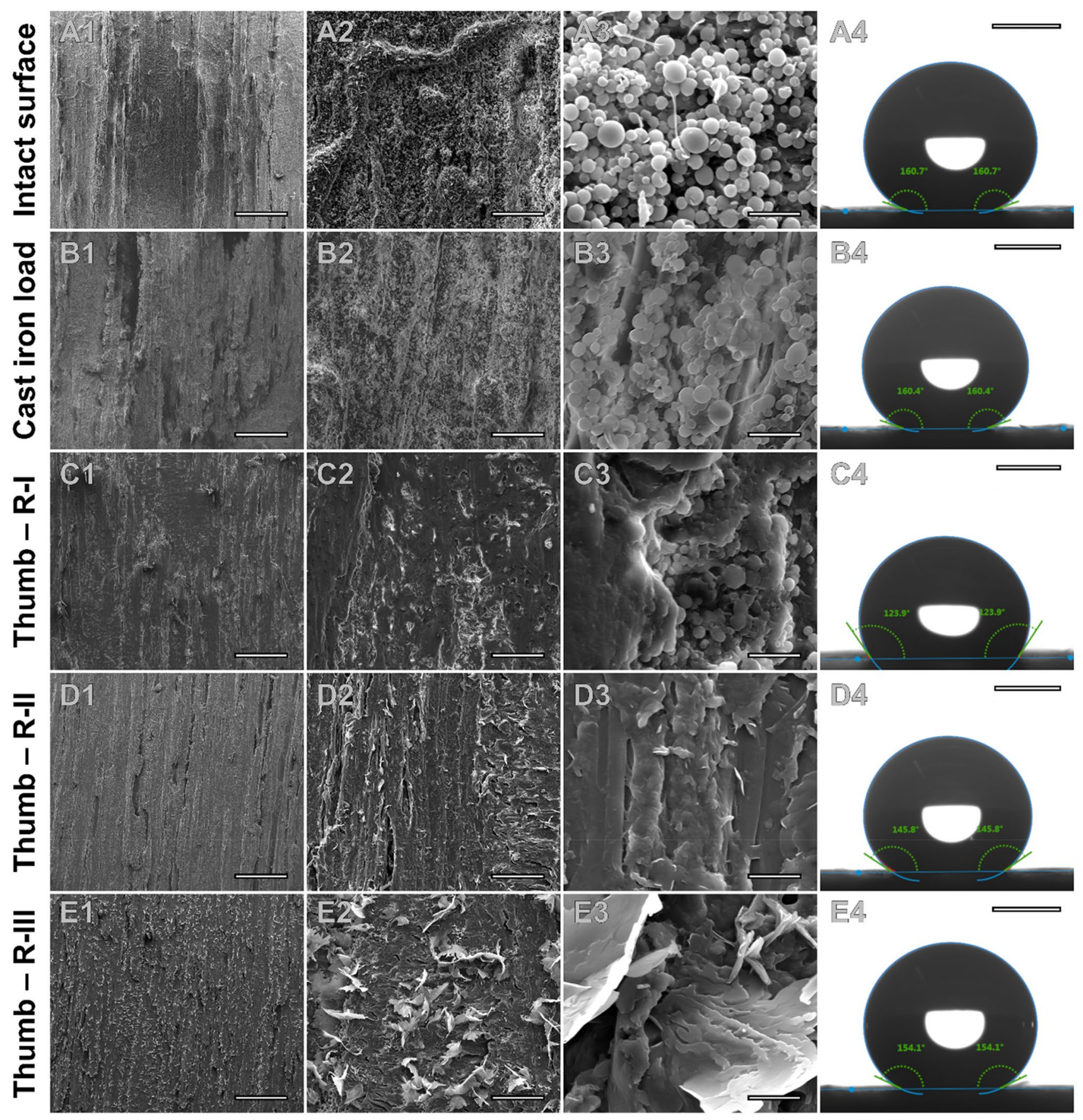

Fig. 4 SEM images of different magnifications (1-3) and representative images of water contact angle measurements (4) of an intact, superhydrophobic specimen (A), a specimen loaded with $10 \mathrm{~kg}$ on $50 \times 50 \mathrm{~mm}^{2}$ for $30 \mathrm{~min}(\mathrm{~B})$, and specimens after $60 \mathrm{~s}$ of thumb rub-

Loading by compression and shear stresses Figure 5 shows the WCA of wood samples exposed to compression stress from a cast iron weight. Even though little mechanical resistance was expected from the small-scaled AKD structures, compression stress did not significantly affect the wettability of the surface. Presumably, the rough bing and consequent recovery at condition R-I (C), R-II (D), and R-III (E), respectively. Scale bars correspond to $500 \mu \mathrm{m}$ (1), $50 \mu \mathrm{m}(2)$, $5 \mu \mathrm{m}(3)$, and $1.000 \mu \mathrm{m}(4)$

underlying wood structure of the specimens prevented full contact, leading only to localized damage in the AKD surface structure. However, using SEM, no noticeable damage was discernible (Fig. 4/B1-3). Since no damage was observed, no recovery experiments were carried out for this variant. 


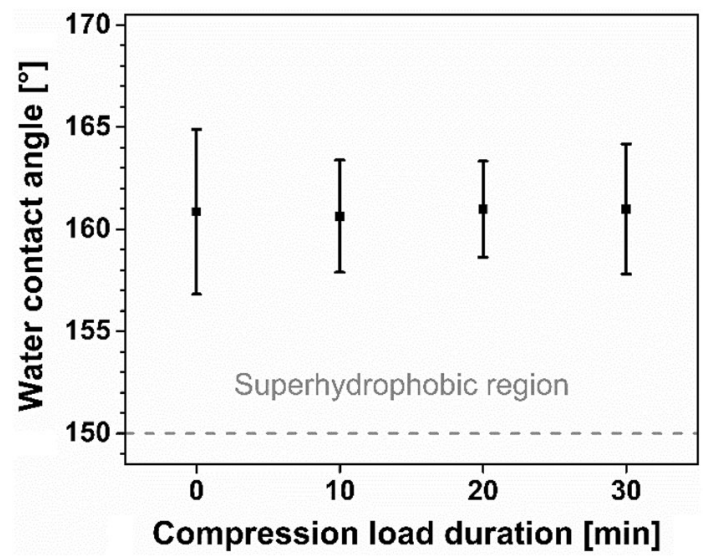

Fig. 5 Water contact angle development after $10 \mathrm{~kg}$ of static load was applied for $30 \mathrm{~min}$ on sample areas of $50 \times 50 \mathrm{~mm}^{2}, \mathrm{n}=16$

As another practical test of the mechanical resistance, superhydrophobic samples were exposed to thumb rubbing for 30 or $60 \mathrm{~s}$. In comparison to the static compression stress, two main differences occurred during this load case. Firstly, the dominant load type applied was repeated shear stress instead of static normal stress, and secondly, a human thumb and the disposable gloves used are soft and could adapt more to the rough structure of the wood samples. Therefore, the proposed protective effect of the wood's roughness for the AKD structures did not apply. The WCAs diminished to approximately $127 \pm 6^{\circ}$ and $123 \pm 5^{\circ}$ after $30 \mathrm{~s}$ and $60 \mathrm{~s}$ of thumb rubbing, respectively (Figs. 6, 4/C4). Further, the sliding angle was significantly affected to a degree where no meaningful measurements could be performed, i.e., the drop remained attached to the surface at any inclination. SEM images showed clear damage and reduced roughness on major parts of the surface area. Most of the spherical and flake-like wax structures observed before the mechanical loading were smeared to rather flat surface areas (Fig. 4/ C1-3). Remaining wax particles were found only in deep recesses of the wood structure. Obviously, their small proportion of the total surface area did not suffice to maintain the high initial level of hydrophobicity.

\subsection{Recovery of wax surface structures}

The simplicity of the preparation process and the use of only AKD wax and water as a transportation medium are major advantages of the described process but cannot provide the required mechanical resistance for many practical, long-term applications. However, the AKD's known ability to selfassemble into specific surface structures (Arminger et al. 2019; Fang et al. 2008; Shibuichi et al. 1997, 1998) gives reason to expect that, under the right conditions, a recovery effect of the surface structure might be possible. Therefore, samples with clearly reduced hydrophobicity after exposure to thumb rubbing underwent three different potential thermal recovery treatments. Figure 6 shows a graphical summary of the WCA developments from the preparation of intact superhydrophobic surfaces to the wetting after the thumb loading and the effects of different recovery conditions. Exemplary
Fig. 6 Development of water contact angle and adhesion before and after mechanical loading by thumb rubbing and after different thermal recovery treatments. The number of water droplets measured for each group and exemplary images of contact angle measurements are given below/next to the standard deviation bars

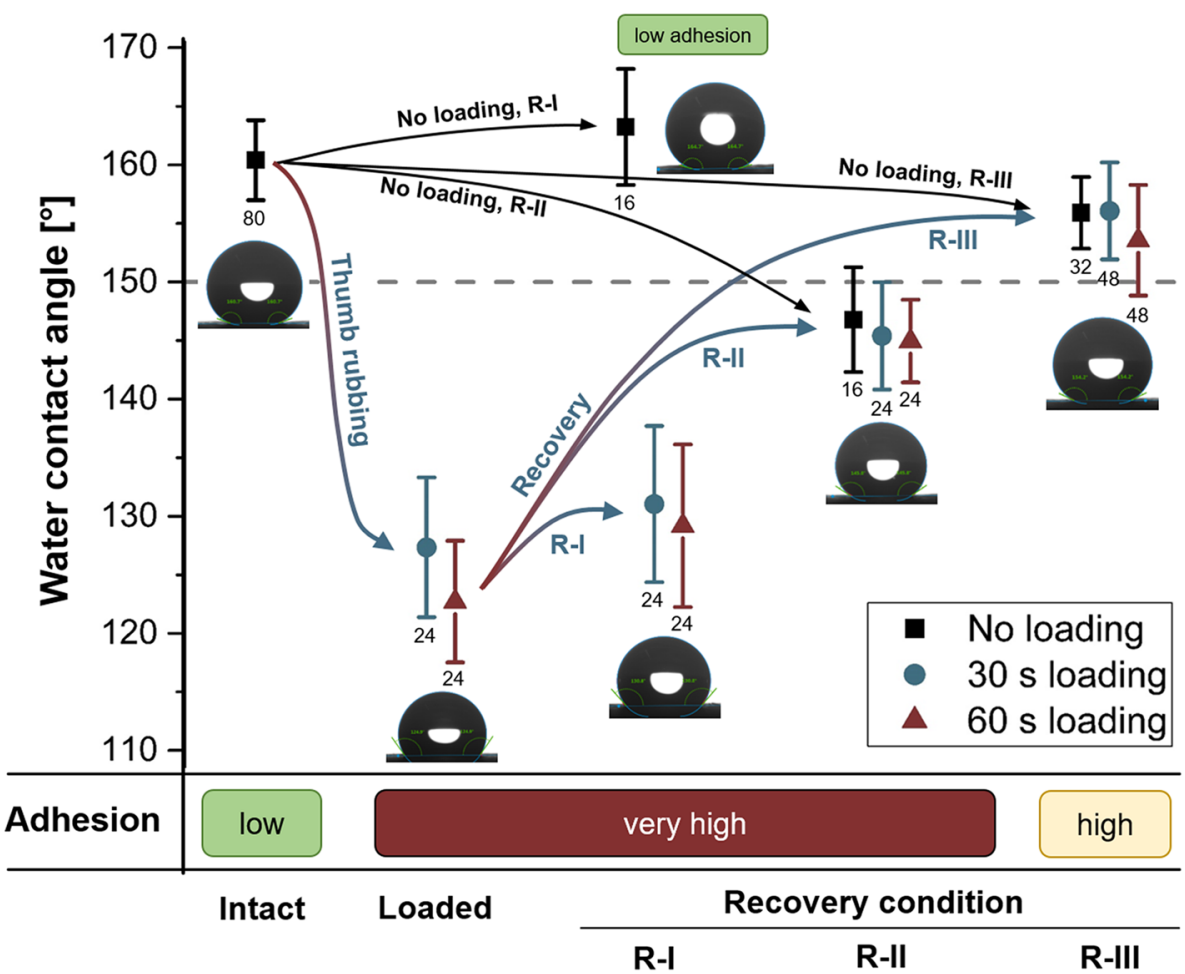


images of the WCA measurements are depicted below the given WCA values. Based on the results of the sliding angle tests, the adhesion of water drops to the samples was categorized in groups of "low" (all sliding angles measured $<90^{\circ}$ ), "high" (more than $50 \%$ of all sliding angles $\geq 90^{\circ}$ ), and "very high" (all sliding angles $\geq 90^{\circ}$, no droplets were rolling off the surface).

Recovery condition R-I (storage at room temperature for $16 \mathrm{~h}$ ) resulted in slightly improved WCAs of $131 \pm 7^{\circ}$ for samples exposed to $30 \mathrm{~s}$ of thumb loading and $129 \pm 7^{\circ}$ for samples exposed to $60 \mathrm{~s}$ of loading. Hence, a tendency of increasing water-repellency over time was indicated but the comparatively small changes in WCAs in combination with large standard deviations did not allow reliable conclusions. Moreover, no noticeable topography changes were recognized during SEM observations (Fig. 4/C1-3), and the samples unambiguously remained in the same range of hydrophobicity.

A second group of samples (R-II) was heated up to $80{ }^{\circ} \mathrm{C}$ followed by abrupt cooling at room temperature. Since $80{ }^{\circ} \mathrm{C}$ is above the melting range of AKD (Fig. 3), a wax layer tightly covering the fiber structure of the wood formed (Fig. 4/D1-3). Furthermore, irregular, straight or curved flake-like structures with lengths in a range of $2-20 \mu \mathrm{m}$ were formed. As a result, the WCA increased to $145^{\circ} \pm 5^{\circ}$ for thumb loading durations of $30 \mathrm{~s}$, and $145^{\circ} \pm 4^{\circ}$ for thumb loading durations of $60 \mathrm{~s}$, respectively. Even though the wetting behavior of samples exposed to recovery treatment R-II was close to the superhydrophobic region, no sliding angles but very high water drop adhesion were observed, i.e., no water drop rolled off these surfaces at inclinations up to $90^{\circ}$.

For a third group of specimens, recovery condition R-III started with heating up to $80^{\circ} \mathrm{C}$ followed by slow cooling to room temperature, allowing for more time for possible structural re-arrangement of the AKD. As shown in Fig. 4/E1-3, comparatively large, dense leaf-like structures formed from AKD during solidification after melting. These thin, frayed structures had widths of 10-50 $\mu \mathrm{m}$ and micron to sub-micron thicknesses, with typical spacing of tens to hundreds of $\mu \mathrm{m}$ with respect to each other. Between these large structures, smaller-scale roughness caused by small platelets, microfissures or other irregularities caused a hierarchical surface of predominantly micron-scale size. The enlarged surface area resulted in mean WCAs of $156 \pm 4^{\circ}$ and $154 \pm 5^{\circ}$ for $30 \mathrm{~s}$ and $60 \mathrm{~s}$ of thumb rubbing, respectively, which means that the superhydrophobicity of the samples was recovered successfully. Same as for R-II, no spherical objects remained after thermal treatment.

Together with the mechanically loaded samples, intact superhydrophobic references were exposed to the same temperatures for comparison. Their WCA development is depicted as the black arrow pathway in Fig. 6. As for the loaded samples, recovery at condition R-I led to a slight increase in WCAs from $160 \pm 3^{\circ}$ to $163 \pm 5^{\circ}$ only due to storage at room temperature for $16 \mathrm{~h}$. Notably, thermal treatments above the melting point resulted in surface properties very similar to samples with prior thumb rubbing. Exposure to temperature profiles led to the melting of AKD spheres and subsequent growth of irregular crystals. Almost identically to the loaded samples, resulting WCAs of $147 \pm 8^{\circ}$ and $156 \pm 3^{\circ}$ were measured after thermal treatments at R-II and R-III, respectively. After the thermal treatments, SEM investigation of previously intact specimens revealed similar topographies to the recovered ones after mechanical damage. Again, increasing density and size of the newly grown crystals from R-II to R-III were observed. SEM images of intact surfaces exposed to the thermal treatments are provided in the Supplementary Information.

Throughout the experiments carried out in the present study, AKD was melted twice after long time of storage: the first melting took place during the preparation of aqueous wax dispersions, the second as a part of the recovery process in R-II and R-III. In both cases, re-solidification lasted for several hours and the wax was never quenched rapidly as described by Fang et al. (2007, 2008). Still, the wax crystals appeared to be in (partly) metastable state and their consequent transformation to the stable state induced the increase in roughness. No active cooling was used in the current experiments, which showed that the formation and even the recovery of superhydrophobic AKD surfaces on wood are possible at streamlined conditions and reduced input of cooling energy.

\section{Conclusion}

The facile, water-driven deposition of small-scale AKD wax structures according to a recent report by Arminger et al. (2019) resulted in superhydrophobic solid wood surfaces with mean water contact angles of more than $160^{\circ}$. The surfaces were surprisingly resistant to static weight loadings. The rough, load bearing wood surfaces protected their hydrophobizing wax structures, resulting in synergistic protection for both materials. However, applied shear forces quickly reduced the roughness and thus the contact angles of the samples. It was discovered that simple thermal treatments can recover sufficient surface structures to regain superhydrophobic properties within hours. For the most efficient condition, i.e., the short heating above the AKD's melting range followed by slow cooling, no quick quenching of the wax crystals or other special environmental conditions were necessary. The possibility of recovering superhydrophobic wax structures could allow the economic realization of water-repellent wood products for applications that are frequently exposed to limited mechanical stresses, 
such as facades, wooden walls or fences, all kinds of packaging applications and many more.

Supplementary Information The online version contains supplementary material available at https://doi.org/10.1007/s00107-022-01793-8.

Acknowledgements We want to thank Pia Solt-Rindler for performing the thermal analysis. Kemira Chemie GesmbH in Krems, Austria, is acknowledged for providing AKD.

Funding Open access funding provided by University of Natural Resources and Life Sciences Vienna (BOKU). Financial support by the Austrian COMET program (COMET K1 centre WOOD, project number 865905 ) is gratefully acknowledged. The funding source was not involved in study design, in the collection, analysis and interpretation of data, in the writing of the report, or in the decision to submit the article for publication.

\section{Declarations}

Conflict of interest The authors declare that they have no conflict of interest.

Open Access This article is licensed under a Creative Commons Attribution 4.0 International License, which permits use, sharing, adaptation, distribution and reproduction in any medium or format, as long as you give appropriate credit to the original author(s) and the source, provide a link to the Creative Commons licence, and indicate if changes were made. The images or other third party material in this article are included in the article's Creative Commons licence, unless indicated otherwise in a credit line to the material. If material is not included in the article's Creative Commons licence and your intended use is not permitted by statutory regulation or exceeds the permitted use, you will need to obtain permission directly from the copyright holder. To view a copy of this licence, visit http://creativecommons.org/licenses/by/4.0/.

\section{References}

Arminger B, Gindl-Altmutter W, Keckes J, Hansmann C (2019) Facile preparation of superhydrophobic wood surfaces via spraying of aqueous alkyl ketene dimer dispersions. RSC Adv 9:24357-24367

Bai X, Shen Y, Tian H, Yang Y, Feng H, Li J (2019) Facile fabrication of superhydrophobic wood slice for effective water-in-oil emulsion separation. Sep Purif Technol 210:402-408

Bao W, Zhang M, Jia Z, Jiao Y, Cai L, Liang D, Li J (2019) Cu thin films on wood surface for robust superhydrophobicity by magnetron sputtering treatment with perfluorocarboxylic acid. Eur J Wood Prod 77:115-123

Barthlott W, Neinhuis C (1997) Purity of the sacred lotus, or escape from contamination in biological surfaces. Planta 202:1-8

Barthlott W, Schimmel T, Wiersch S, Koch K, Brede M, Barczewski M, Walheim S, Weis A, Kaltenmaier A, Leder A (2010) The Salvinia paradox: superhydrophobic surfaces with hydrophilic pins for air retention under water. Adv Mater 22:2325-2328

Bhushan B, Jung YC (2011) Natural and biomimetic artificial surfaces for superhydrophobicity, self-cleaning, low adhesion, and drag reduction. Prog Mater Sci 56:1-108

Bormashenko E (2009) Young, Boruvka-Neumann, Wenzel and Cassie-Baxter equations as the transversality conditions for the variational problem of wetting. Colloids Surf A 345:163-165
Carré A, Mittal KL (2009) Superhydrophobic surfaces. CRC Press, Boca Raton

Chen K, Zhou S, Yang S, Wu L (2015) Fabrication of all-water-based self-repairing superhydrophobic coatings based on UV-responsive microcapsules. Adv Func Mater 25:1035-1041

Chen K, Wu Y, Zhou S, Wu L (2016) Recent development of durable and self-healing surfaces with special wettability. Macromol Rapid Commun 37:463-485

Dalawai SP, Aly MAS, Latthe SS, Xing R, Sutar RS, Nagappan S, Ha C-S, Sadasivuni KK, Liu S (2020) Recent advances in durability of superhydrophobic self-cleaning technology: a critical review. Progress Org Coat 138:105381

Darmanin T, Guittard F (2015) Superhydrophobic and superoleophobic properties in nature. Mater Today 18:273-285

Ejenstam L, Ovaskainen L, Rodriguez-Meizoso I, Wågberg L, Pan J, Swerin A, Claesson PM (2013) The effect of superhydrophobic wetting state on corrosion protection-The AKD example. J Colloid Interface Sci 412:56-64

Fang W, Mayama H, Tsujii K (2007) Spontaneous formation of fractal structures on triglyceride surfaces with reference to their super water-repellent properties. J Phys Chem B 111:564-571

Fang W, Mayama H, Tsujii K (2008) Formation mechanism of super water-repellent fractal surfaces of alkylketene dimer. Colloids Surf A 316:258-265

Feng L, Li S, Li Y, Li H, Zhang L, Zhai J, Song Y, Liu B, Jiang L, Zhu D (2002) Super-hydrophobic surfaces: from natural to artificial. Adv Mater 14:1857-1860

Huth MA, Huth A, Koch K (2018) Morphological diversity of $\beta$-diketone wax tubules on Eucalyptus gunnii leaves and real time observation of self-healing of defects in the wax layer. Aust J Bot 66:313-324

Janesch J, Arminger B, Gindl-Altmutter W, Hansmann C (2020) Superhydrophobic coatings on wood made of plant oil and natural wax. Progress Org Coat 148:105891

Jia S, Liu M, Wu Y, Luo S, Qing Y, Chen H (2016) Facile and scalable preparation of highly wear-resistance superhydrophobic surface on wood substrates using silica nanoparticles modified by VTES. Appl Surf Sci 386:115-124

Jia S, Chen H, Luo S, Qing Y, Deng S, Yan N, Wu Y (2018) Onestep approach to prepare superhydrophobic wood with enhanced mechanical and chemical durability: driving of alkali. Appl Surf Sci 455:115-122

Koch K, Ensikat H-J (2008) The hydrophobic coatings of plant surfaces: epicuticular wax crystals and their morphologies, crystallinity and molecular self-assembly. Micron 39:759-772

Koch K, Bhushan B, Ensikat H-J, Barthlott W (2009) Self-healing of voids in the wax coating on plant surfaces. Philos Trans R Soc A Math Phys Eng Sci 367:1673-1688

Li Y, Li L, Sun J (2010) Bioinspired self-healing superhydrophobic coatings. Angew Chem 122:6265-6269

Liu C, Wang S, Shi J, Wang C (2011) Fabrication of superhydrophobic wood surfaces via a solution-immersion process. Appl Surf Sci 258:761-765

Manna U, Lynn DM (2013) Restoration of superhydrophobicity in crushed polymer films by treatment with water: self-healing and recovery of damaged topographic features aided by an unlikely source. Adv Mater 25:5104-5108

Minami T, Mayama H, Nakamura S, Yokojima S, Shen J-W, Tsujii K (2008) Formation mechanism of fractal structures on wax surfaces with reference to their super water-repellency. Soft Matter 4:140-144

Neinhuis C, Koch K, Barthlott W (2001) Movement and regeneration of epicuticular waxes through plant cuticles. Planta 213:427-434

Onda T, Shibuichi S, Satoh N, Tsujii K (1996) Super-water-repellent fractal surfaces. Langmuir 12:2125-2127 
Pandit SK, Tudu BK, Mishra IM, Kumar A (2020) Development of stain resistant, superhydrophobic and self-cleaning coating on wood surface. Progress Organic Coat 139:105453

Pierce E, Carmona F, Amirfazli A (2008) Understanding of sliding and contact angle results in tilted plate experiments. Colloids Surf A 323:73-82

Quan C, Werner O, Wågberg L, Turner C (2009) Generation of superhydrophobic paper surfaces by a rapidly expanding supercritical carbon dioxide-alkyl ketene dimer solution. J Supercrit Fluids 49:117-124

Saji VS (2020) Wax-based artificial superhydrophobic surfaces and coatings. Colloids Surf A Physicochem Eng Aspects 602:125132

Sam EK, Sam DK, Lv X, Liu B, Xiao X, Gong S, Yu W, Chen J, Liu J (2019) Recent development in the fabrication of self-healing superhydrophobic surfaces. Chem Eng J 373:531-546

Shah SM, Zulfiqar U, Hussain SZ, Ahmad I, Hussain I, Subhani T (2017) A durable superhydrophobic coating for the protection of wood materials. Mater Lett 203:17-20

Shibuichi S, Onda T, Satoh N, Tsujii K (1996) Super water-repellent surfaces resulting from fractal structure. J Phys Chem 100:19512-19517

Shibuichi S, Onda T, Satoh N, Tsujii K (1997) Super water-repellent surfaces resulting from fractal structure. II. J Jpn Oil Chem Soc 46:649-659 (713)

Shibuichi S, Yamamoto T, Onda T, Tsujii K (1998) Super water-and oil-repellent surfaces resulting from fractal structure. J Colloid Interface Sci 208:287-294

Verho T, Bower C, Andrew P, Franssila S, Ikkala O, Ras RH (2011) Mechanically durable superhydrophobic surfaces. Adv Mater 23:673-678

Wang C, Piao C, Lucas C (2011a) Synthesis and characterization of superhydrophobic wood surfaces. J Appl Polym Sci 119:1667-1672

Wang H, Xue Y, Ding J, Feng L, Wang X, Lin T (2011b) Durable, self-healing superhydrophobic and superoleophobic surfaces from fluorinated-decyl polyhedral oligomeric silsesquioxane and hydrolyzed fluorinated alkyl silane. Angew Chem 123:11635-11638

Wang S, Liu C, Liu G, Zhang M, Li J, Wang C (2011c) Fabrication of superhydrophobic wood surface by a sol-gel process. Appl Surf Sci 258:806-810

Wenzel RN (1936) Resistance of solid surfaces to wetting by water. Ind Eng Chem 28:988-994

Wu Y, Jia S, Qing Y, Luo S, Liu M (2016) A versatile and efficient method to fabricate durable superhydrophobic surfaces on wood, lignocellulosic fiber, glass, and metal substrates. J Mater Chem A 4:14111-14121

Xia M, Yang T, Chen S, Yuan G (2020) Fabrication of superhydrophobic Eucalyptus wood surface with self-cleaning performance in air and oil environment and high durability. Colloid Interface Sci Commun 36:100264

Xue C-H, Zhang Z-D, Zhang J, Jia S-T (2014) Lasting and selfhealing superhydrophobic surfaces by coating of polystyrene/ $\mathrm{SiO} 2$ nanoparticles and polydimethylsiloxane. J Mater Chem A 2:15001-15007

Yan YY, Gao N, Barthlott W (2011) Mimicking natural superhydrophobic surfaces and grasping the wetting process: A review on recent progress in preparing superhydrophobic surfaces. Adv Coll Interface Sci 169:80-105

Young T (1805) III. An essay on the cohesion of fluids. Philos Trans R Soc 95:65-87

Zhang X, Shi F, Niu J, Jiang Y, Wang Z (2008) Superhydrophobic surfaces: from structural control to functional application. J Mater Chem 18:621-633

Zhu X, Zhang Z, Men X, Yang J, Wang K, Xu X, Zhou X, Xue Q (2011) Robust superhydrophobic surfaces with mechanical durability and easy repairability. J Mater Chem 21:15793-15797

Publisher's Note Springer Nature remains neutral with regard to jurisdictional claims in published maps and institutional affiliations. 